\title{
DISTRIBUSI SUMBING BIBIR DAN LANGIT-LANGIT DI CLEFT LIP AND PALATE CENTER FAKULTAS KEDOKTERAN UNIVERSITAS MUHAMMADIYAH MALANG INDONESIA
}

\author{
Ruby Riana A \\ SMF/Bagian Bedah Fakultas Kedokteran University Muhammadiyah Malang, Indonesia
}

Abstract

Objective: The purpose of this study was to investigate the distribution of different cleft pattern by the age of first operation, sex, side of cleft of Cleft Lips (CL), cleft palate (CP) and cleft lip and palate patients (CLP), and education level parents in Cleft Lip and Palate Center in Faculty of Medicine, University of Malang Mubammadiyah (CLPC FM UMM). Study design: Four hundred twenty-nine patients attending the CLPC FM UMM from January 2014 to December 2016 were studied. Most patients came from East Java, Indonesia and the surrounding areas. Result: Highest frequency of CL in CLPC FM UMM is in the age group 0-1 y.o, CP patients in the age group 1-5 y.o, while most CLP patients in the age group 1-5 y.o. Cleft lip and palate (61.31\%) was most frequently found, followed by cleft lip with or without alveolus $(33.33 \%)$ and cleft palate $(5.36 \%)$. Cleft lip and palate, cleft lip with or without alveolus and cleft palate occurred more frequently in males. Left-sided unilateral clefts were observed in $57.34 \%$ of patients compared to right-sided unilateral clefts in $21.21 \%$, the rest is bilateral cleft $21.45 \%$. The unilateral complete CLP (45.22\%) was most frequently found, followed by the unilateral incomplete CL (18.41\%). Most of the parent's education were elementary school graduated. Conclusion: The most frequent profile in the affected population were males, left sided unilateral complete CLP were most affected.

\section{Pendahuluan}

Sumbing orofacial non-syndromic, seperti sumbing bibir (SB), sumbing bibir dan langit-langit (SBL), serta sumbing langit-langit (SL), meliputi kelainan pada bibir dan kavitas oral, merupakan cacat bawaan pada kepala leher tersering. Sumbing bibir dengan atau tanpa langit-langit terjadi pada 1/1,000 kelahiran dan memiliki berbagai sebab (Arun and Randall 2007, Aylsworth 1996, Bailey and Derkay 2001). Faktor penyebab terdiri dari faktor lingkungan baik sebab geografis atau sosioekonomi dan faktor genetik (Mossey and Little 2002).

Kejadian cacat ini mendorong Fakultas Kedokteran Universitas Muhammadiyah Malang (FK UMM) mengadakan kegiatan pengabdian masyarakat berupa operasi gratis sumbing bibir dan langit-langit melalui sebuah sentra yang disebut Sentra Sumbing Bibir dan Langit-langit (Cleft Lip and Palate) CLP Center FK UMM sejak tahun 2008. Kegiatan ini akan membantu pasien yang tidak mampu sekaligus memperkenalkan Sentra Sumbing Bibir dan Langit-langit (CLP Center) FK UMM. Sentra Sumbing Bibir dan Langitlangit FK UMM adalah sebuah lembaga non profit yang merupakan pusat pelayanan terpadu bagi anak, remaja dan semua pasien sumbing bibir dan langit-langit yang dimulai pada usia 0 sampai dewasa. Melalui pusat rekonstruksi ini pasien mendapat bantuan medis di bawah satu atap oleh satu tim dokter dari berbagai spesialisasi. Jumlah operasi sampai saat ini telah mencapai sekitar 2000. Pasien berasal dari Jawa Timur dan sekitarnya.

Jumlah operasi yang cukup banyak mendorong peneliti untuk mengetahui distribusi jenis sumbing berdasarkan usia saat operasi pertama kali, jenis kelamin, tempat tinggal, pendidikan orang tua dan jenis sumbing dari SB, SL serta SBL di CLP Center FK UMM.

\section{Metode Penelitian}

Sampel yang digunakan dalam penelitian ini adalah pasien CLP Center FK UMM tahun 2014-2016 sebanyak 429 pasien.

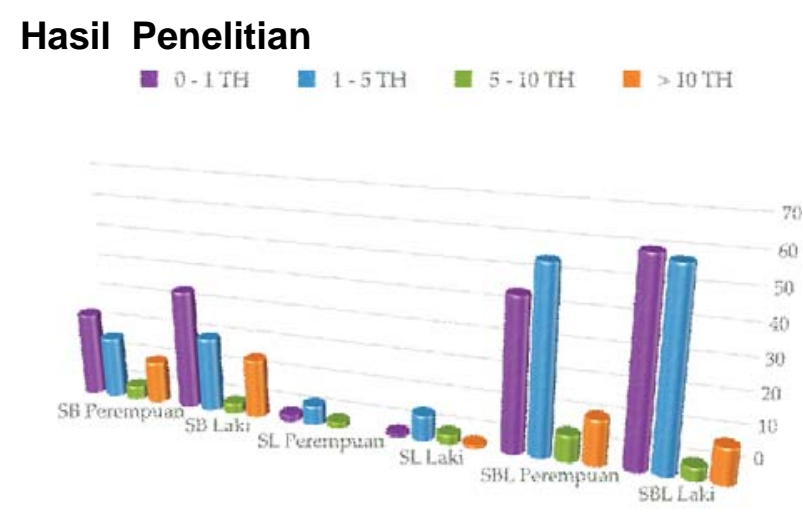

Gambar 1. Distribusi SB, SL dan SBL berdasarkan usia

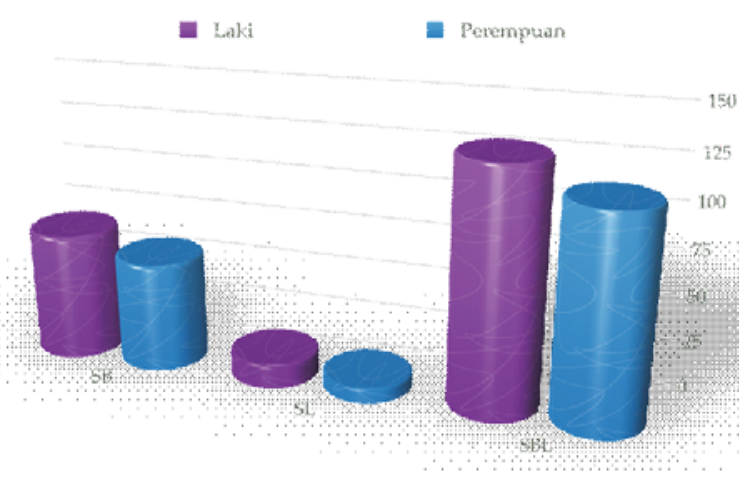

Gambar 2. Distribusi SB, SL dan SBL berdasarkan jenis kelamin 


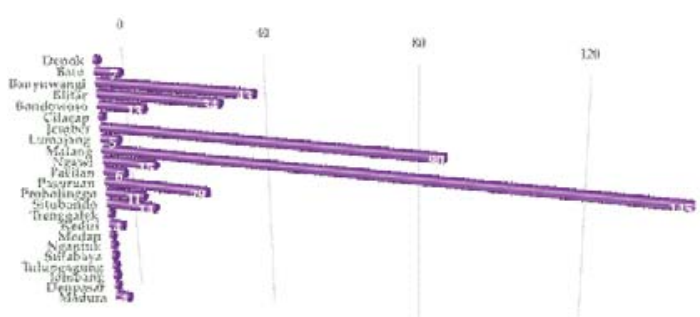

Gambar 3. Distribusi SB, SL, SBL berdasarkan tempat tinggal

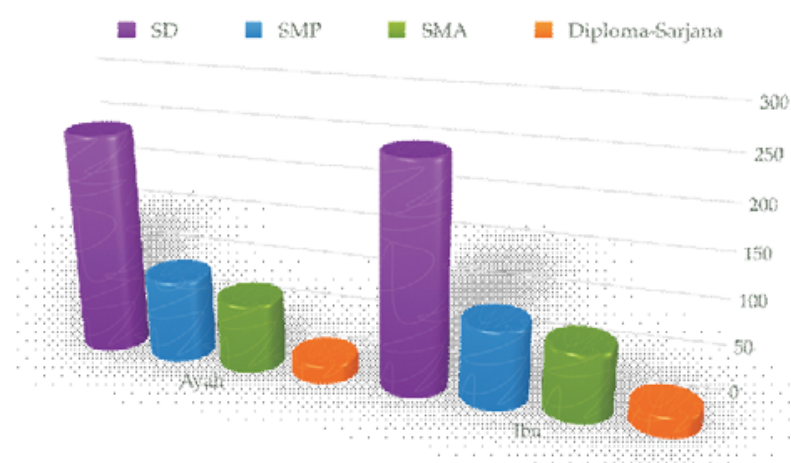

Gambar 4. Distribusi SB, SL dan SBL berdasarkan pendidikan orang tua

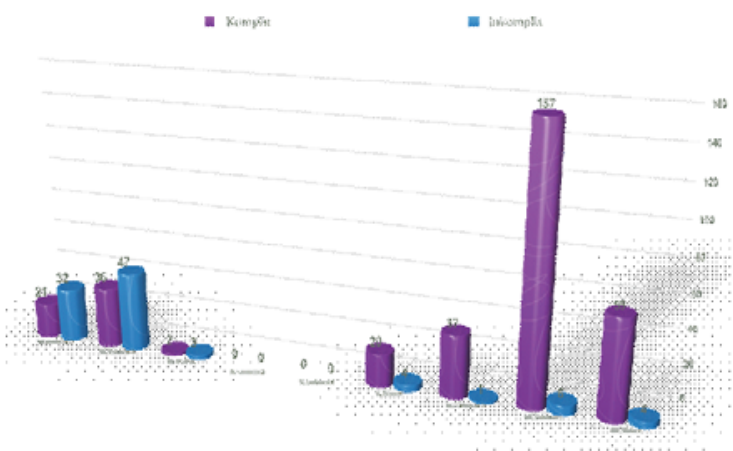

Gambar 5. Distribusi SB, SL dan SBL berdasarkan jenis sumbing

\section{Pembahasan}

Sumbing bibir terbanyak pada usia 0-1 tahun. Sumbing langit-langit terbanyak pada usia 1-5 tahun, sedang SBL pada usia 1-5 tahun. Hal ini terkait dengan tahapan operasi yang berlaku di CLP Center FK UMM, dimana cheiloraphy dilakukan mulai usia 3 bulan, palatoraphy usia 10-18 bulan, atau cheilopalatoraphy bersamaan pada usia 10-24 bulan.

Sumbing Bibir dan Langit-langit paling sering ditemukan (total 263 atau 61,315\%), diikuti oleh SB (total 143 atau 33,33\%) dan SL (total 23 atau 5,36\%). Hal ini sesuai dengan publikasi oleh Mossey and Little 2002 yang menyebutkan bahwa SB dan SBL memiliki angka kejadian yang tinggi di Amerika Latin dan Asia, namun rendah di Israel, Afrika Selatan dan Eropa Selatan (Mossey and Little 2002, Yazdy, et al. 2007, Sivertsen, et al. 2008).

Kejadian SBL, SB dan SL lebih sering ditemukan pada laki. Hal ini sesuai dengan penelitian yang dilakukan di Meksiko selama 10 tahun dari 1990-1999, didapatkan kejadian SB dan SBL lebih sering pada laki (Blanco-Davila 2003).
Namun berbeda dengan kejadian SL yang lebih sering pada perempuan (Blanco-Davila 2003, Mossey, Little and Munger, et al. 2009, Mossey and Little 2002). Perbedaan ini bisa disebabkan kejadian SL lebih jarang ditemukan karena SL merupakan cacat yang tersembunyi (Millard 1976, Yazdy, et al. 2007).

Sumbing unilateral sisi kiri lebih sering ditemukan (57.34\%) dibanding sumbing unilateral sisi kanan (21.21\%), sisanya adalah sumbing bilateral $(21.45 \%)$. Penelitian di Meksiko dan Philippines menghasilkan hal yang sama yaitu sumbing unilateral sisi kiri lebih sering ditemukan dari sisi kanan dan diikuti oleh bilateral (Blanco-Davila 2003, Murray, et al. 1997).

Sumbing Bibir dan Langit-langit unilateral komplit $(45.22 \%)$ adalah yang paling sering ditemukan, diikuti oleh SB unilateral inkomplit (18.41\%). Sebagian besar orangtua berpendidikan Sekolah Dasar. Tempat tinggal pasien sebagian besar berada di Malang.

\section{Daftar Pustaka}

Arun, KG, and M Randall. "Embryology of the head and neck." In Grabb and Smith's Plastic Surgery, by Charles H. Thorne, edited by Charles H. Thorne, 179-90. Philadelphia: Lippincott Williams \& Wilkins, 2007.

Aylsworth, AS. "Genetic Considerations in Craniofacial Birth Defects." In Facial Clefts and Craniosynostosis, Principles and Management, by TA Turvey, KWL Vig and RJ Fonseca, edited by TA Turvey, KWL Vig and RJ Fonseca, 76-91. Philadelphia: W.B. Saunders Company, 1996.

Bailey, BJCK, and CS Derkay. Head and Neck SurgeryOtolaryngology. 3. Edited by Derkay CS Bailey BJCK. Philadelphia: Lippincott Williams \& Wilkins, 2001.

Blanco-Davila, F. "Incidence of Cleft Lip and Palate in the Northeast of Mexico: A 10-Year Study." The Journal of Craniofacial Surgery 14, no. 4 (July 2003).

Gilarsi, TR. "Sumbing Bibir, Faktor Penyebab dan Penanggulangannya." Medika 4 (2001): 248-250.

Millard, DR Jr. Cleft Craft. Boston: Little, Brown and Company, 1976.

Mossey, PA, and J Little. "Epidemiology of oral clefts: an international perspective." In Cleft lip and palate: from origin to treatment, by Wyszynski DF, edited by Wyszynski DF, 127-58. New York: Oxford University Press, 2002.

Mossey, PA, J Little, RG Munger, MJ Dixon, and WC Shaw. "Cleft lip and palate." Lancet 374 (2009): 1773-85 .

Murray, JC, et al. "Clinical and epidemiologic studies of cleft lip and palate in the Philippines." Cleft Palate Craniofacial Journal 34 (1997): 7-10.

Sivertsen, A, AJ Wilcox, R Skjaerven, and et al. "Familial risk of oral Clefts by morphological type and severity: population based cohort study of first degree relatives." BMJ. 336 , no. 7641 (2008): 432-434.

Yazdy, MM, MA Honein, SA Rasmussen, and JL Frias. "Priorities for future public health research in orofacial clefts." Cleft Palate Craniofac J 44 (2007): 351-7. 